\title{
O Papel Docente na Formação do Profissional de Computação para Além da Sala de Aula: Um Relato de Experiência
}

\author{
Claudia Pinto Pereira* \\ *Departamento de Ciências Exatas, Universidade Estadual de Feira de Santana e Escola de \\ Engenharia e TI, Universidade Salvador, Feira de Santana, Brasil. \\ E-mail: caupinto.sena@gmail.com. \\ Naan Silva Cardoso \\ •Departamento de Tecnologia, Universidade Estadual de Feira de Santana, Feira de Santana, \\ Brasil. \\ E-mail: naancardoso@gmail.com.
}

\section{Resumo}

Atualmente, o ensino superior brasileiro tem, cada vez mais, dado ênfase ao ensino, a pesquisa e a extensão, tornando-os indispensáveis para a formação do profissional de qualquer área. Pensando nessa importância, o presente artigo apresenta o relato de uma experiência de orientação na pesquisa e na extensão, da Universidade Estadual de Feira de Santana e Universidade Salvador, realizada entre 2012 e 2016, destacando e analisando os desafios, as potencialidades e os impactos enfrentados e vivenciados por docentes e discentes, nesse percurso, e o papel do orientador.

Palavras-chave: Educação, Pesquisa, Extensão, Orientação.

\begin{abstract}
Currently, Brazilian higher education has increasingly emphasized teaching, research and extension, making them indispensable for the training of professionals in any area. Thinking about this importance, this paper presents an experience of orientation in the research and extension of the University of Feira de Santana and University Salvador, carried out between 2012 and 2016,
\end{abstract}


84 ISSN: 2358-1271. Int. J. of Alive Eng. Educ. (IJAEEdu). (Online). Goiânia, v. 4, n. 1, p. 83-102, jan./june 2017.

highlighting and analyzing the challenges, the potentialities and the impacts faced and experienced by professors and students in this course and the role of the advisor.

Keywords: Education, Research, Extension, Orientation.

\section{Resumen}

En la actualidad, la educación superior brasileña ha destacado cada vez más la enseñanza, investigación y extensión, haciéndolos indispensables para la formación de los profesionales de cualquier área. Teniendo en cuenta esta importancia, este artículo presenta la historia de una anécdota de orientación en investigación y extensión, de la Universidad Estatal de Feira de Santana y la Universidad Salvador, llevada a cabo entre 2012 y 2016, resaltando y analizando los desafíos, el potencial y los impactos enfrentados y vividos por profesores y estudiantes en este recorrido, y el papel del orientador.

Palabras claves: Educación, Investigación, Extensión, Orientación. 


\section{Introdução}

A premissa que regula o processo de ensino-aprendizagem, formado pelo tripé ensino, pesquisa e extensão nas Universidades, detentoras de conhecimento e de autonomia didáticocientífica, é amparada pela indissociabilidade, que trata da importância da igualdade entre essa trindade para o processo de formação.

Essa tríade é parte essencial na construção de um conhecimento com qualidade, produtividade e competência na comunidade acadêmica, uma vez que o ensino, a pesquisa e a extensão ajudam a formar pensadores e criadores, revelando o verdadeiro significado social do trabalho acadêmico.

Assim, "enquadradas pelo princípio da indissociabilidade, a extensão e a pesquisa tornamse consequências naturais da docência, referências para que o ensino não se torne abstrato nem desligado das realidades locais"1. Dessa forma, a docência vai além da sala de aula e de conteúdos trabalhados neste espaço, para atuações em outros espaços sociais e comunitários. O docente é um dos elementos essenciais na construção dessa tríade e na conscientização da importância da formação de estudantes cidadãos, pesquisadores e conscientes de sua responsabilidade social.

Portanto, "trabalhar pela indissociabilidade entre o ensino, a pesquisa e a extensão significa preocupar-se em constituir uma formação não segregada, como eram as cátedras do início do ensino superior" . Dessa maneira, Corrêa afirma que: "Inserida no seu tempo e espaço, em sua indissociabilidade com o ensino e a pesquisa, a extensão universitária poderá contribuir e participar significativamente em processos de desenvolvimento regional e nacional, de construção das políticas públicas, do sistema social, dos direitos humanos, da democracia, da vida e da paz."3

Consequentemente, uma vez refletida e materializada a indissociabilidade entre o ensino, a pesquisa e a extensão, é importante assegurar que a Universidade gere conhecimentos e que, ao mesmo tempo, torne-os alcançáveis, a fim de formar novos profissionais voltados aos mais distintos ramos da Sociedade. Isso se aplica para profissionais de qualquer área do conhecimento, inclusive os de Computação, que precisam estar preparados para os desafios técnicos e sociais que encontrarão em suas trajetórias acadêmica e profissional.

Nessa perspectiva, esse artigo propõe relatar a experiência de orientação de estudantes de Computação, de 2012 a 2016, tanto na pesquisa quanto na extensão, nas Universidade Estadual de Feira de Santana e Universidade Salvador, ambas da cidade de Feira de Santana, Bahia. A percepção dos avanços cognitivos e técnicos dos estudantes da área de Computação, orientados, neste período, foi um dos motivos impulsionadores deste trabalho, que objetiva relatar os desafios, as potencialidades e as vantagens advindos desse processo, seja na pesquisa e/ou extensão. Além disso, outro motivo foi a inquietação em perceber, tanto no ensino superior público quanto no privado, visões tantas vezes distorcidas do papel e valorização docente nesse processo de orientação, seja na perspectiva institucional ou na perspectiva de outros docentes.

De forma geral, o artigo se divide em seis seções, incluindo a Introdução. A Seção 2 traz considerações teóricas a respeito do papel das atividades de extensão para a formação discente. A Seção 3 esclarece o papel das atividades de pesquisa para a formação discente. A Seção 4 apresenta os procedimentos metodológicos e breve relato da experiência. A Seção 5 traz a apresentação e discussão dos resultados. Por fim, são apresentadas as conclusões do trabalho. 


\section{O Papel das Atividades de Extensão para a Formação Discente}

Ao refletir a Universidade, percebe-se que a mesma é composta por formação de profissionais, geração e difusão de conhecimentos, e, por isso, detentora de um processo complexo face à sua própria pluralidade diante do encargo acadêmico. Diante deste contexto, encontra-se a extensão universitária, que reúne e demonstra uma variedade de teorias e práticas, abrindo um novo olhar entre a sabedoria popular e os conhecimentos técnicos e científicos, entre a Universidade e a Comunidade.

O Plano Nacional de Extensão Universitária (PNExt) em seu Art $2^{\circ}$ institui que "a Extensão é considerada como a atividade acadêmica que articula o Ensino e a Pesquisa e viabiliza a relação entre Universidade e Sociedade"7.

Sendo assim, entende-se que a extensão tem como finalidade determinar a troca de saberes entre a Universidade e a Sociedade, buscando o desenvolvimento de atividades com o intuito de promover a produção do conhecimento, o que caracteriza a extensão universitária como uma via de mão dupla. Assim, a relação entre a Universidade e a Sociedade, promovida pela extensão, deve buscar meios através de projetos, tais como cursos, eventos e palestras, com o propósito de atingir as necessidades da comunidade, a fim de proporcionar melhoria na qualidade de vida das pessoas envolvidas.

Para Serrano, alguns objetivos certificam a extensão universitária com uma concepção cidadã, entre eles: "reafirmar a extensão universitária como processo acadêmico definido e efetivado em função das exigências da realidade, indispensável na formação do aluno, na qualificação do professor e no intercâmbio com a Sociedade".6 .

Assim, Arroyo e Rocha asseguram que: "As relações da Universidade com a Sociedade, através da extensão universitária, devem ser realizadas com a principal tarefa de preocuparse com a formação do cidadão, em duplo sentido: dos novos profissionais que irão atuar nos diversos setores sociais e dos membros da comunidade, o público externo a quem estas ações extensionistas se dirigem, buscando contribuir, concretamente, para a construção de melhores condições de cidadania." 2

Deste modo, "a extensão deve ser necessária para o processo formativo da comunidade acadêmica e também deve contribuir para viabilizar as transformações necessárias da Sociedade" ${ }^{4}$.

Como forma de garantir esse processo formativo junto à comunidade acadêmica, o professor assume um papel de extrema importância e também agrega vasta experiência com a extensão, uma vez que novas práticas passam a ser adotadas, fazendo com que o mesmo se desprenda do modelo clássico da sala de aula, "professor-aluno", para "alunocomunidade", formando um novo conceito de sala de aula e passando a assumir um novo papel (coparticipante, orientador, tutor, coordenador).

A extensão pode, ainda, dar suporte ao professor com relação ao processo avaliativo dos discentes participantes, utilizando-se de outros critérios, tais como carga horária dedicada, frequência, atividades desenvolvidas, empenho e desempenho do discente, entre outros, para enriquecer as avaliações qualitativas, agregando valor no processo educacional.

Por outro lado, a formação do estudante enquanto Universidade deve ir além da obtenção de conhecimentos técnico-científicos, uma vez que estes propendem a se exaurir quando não são agregados à realidade. Com isso, entende-se que a aprendizagem precisa incentivar o estudante a "pensar" e a "fazer", através de uma interação formada por conceitos, metodologias e práticas, gerando o desenvolvimento de relações interpessoais entre a instituição, os profissionais e as pessoas. Portanto, "a participação do aluno nas atividades de extensão será mandatória, parte essencial de sua formação técnica e cidadã"’3. 


\section{O Papel das Atividades de Pesquisa para a Formação Discente}

Sabe-se que ensino, pesquisa e extensão possuem limites e particularidades voltados ao desempenho dos alunos nas atividades desenvolvidas. A pesquisa, por sua vez, é uma atividade que acontece naturalmente a partir do engajamento social, ultrapassando os muros entre o conhecimento científico e o saber popular. À medida que o ensino é agregado ao conhecimento gerado através da pesquisa e das atividades de extensão, obtêm-se um maior valor e importância para a comunidade acadêmica.

Nesse sentido, Andrade e Moita afirmam que "a pesquisa é uma atividade que decorre naturalmente do compromisso social de uma instituição orientada pela superação das distâncias entre os saberes científico e popular"

Dessa forma, a fim de estreitar essas distâncias, o professor atua como um importante elo, que ao intervir na pesquisa e na extensão universitárias, tende a enriquecer e amadurecer ainda mais esse processo, formando novos pesquisadores com pensamento crítico e comprometimento com a interposição social, além de manter-se atualizado com as mudanças recentes que a ciência pode germinar em relação à Sociedade. Consequentemente, percebe-se que a pesquisa e a extensão culminam no ensino e se retroalimentam deste.

Por este ângulo, completamente relacionadas ao ensino, é que a pesquisa e a extensão usufruirão, decerto, a máxima relevância na formação do ensino superior. Desse modo, Martins contempla que: "Se por um lado, o ensino coloca o aluno em relação com o produto da ciência, a pesquisa o coloca em relação como o seu desenvolvimento instrumentalizando-o para produzir conhecimentos a partir de sua futura atuação profissional ou em situações planejadas especificamente para este fim." ${ }^{5}$

Sendo assim, a pesquisa se mostra como um fator importante na formação dos discentes, fazendo com que os mesmos perpassem pelo conhecimento científico até a reflexão dos novos saberes, entendendo a importância de pensar e experimentar as atividades postuladas de investigação, metodologia e criação. Nesse contexto, "o professor que se propõe a pesquisar tem uma gama imensa e pouco explorada de questões que envolvem o conhecimento da realidade nas suas relações com o 'o que', 'o por que', 'o como', 'o para quem' ensinar"19 e, além disso, a pesquisa é um dos caminhos de transformação e, se bem utilizada pelo professor, "poderá assumir sua função social e contribuir não só para tornar a escola uma instituição menos reprodutiva e mais criativa, como tornar o professor um agente de sua própria formação e de seu aprender a ensinar"19.

\section{Procedimentos Metodológicos e Breve Relato da Expe- riência}

O relato de experiência deste trabalho corresponde a um período de 5 anos, de 2012 a 2016, de orientação de 14 estudantes dos cursos de Engenharia de Computação e Sistemas de Informação, respectivamente da Universidade Estadual de Feira de Santana e Universidade Salvador (Campus Feira). O objetivo é discorrer sobre a orientação destes estudantes, neste período, sobre os desafios inerentes ao processo, tanto do ponto de vista docente quanto discente, assim como as potencialidades das atividades de pesquisa e extensão no processo de ensino aprendizagem e os impactos para a Universidade, comunidade, docentes e discentes. Portanto, o foco não é o relato dos projetos de pesquisa/extensão, mas como essas atividades são percebidas pelos discentes e o quanto o docente pode colaborar nesta caminhada.

Para a coleta de dados, foi utilizado um formulário com questões fechadas e abertas, 
para avaliação do percurso discente, aplicado aos 14 participantes, de maneira online, além dos próprios relatos e posicionamentos dos estudantes e a percepção do docente/orientador. Os resultados serão analisados de maneira qualitativa, com a apresentação de falas, relatos e dados numéricos associados. A pesquisa qualitativa, embora diferente da quantitativa, não invalida a pesquisa, muito pelo contrário, dá a ela uma interlocução com a realidade e os autores sociais, sendo caracterizada por Macedo como um rigor outro, um rigor fecundo, no qual a pesquisa é "dialogicizada e dialeticizada com todos os conflitos e debates a ela necessários" .

A intenção é uma análise inicial de um cenário que se repete em várias instituições de ensino, no qual estudantes se envolvem com atividades de pesquisa e extensão, desconhecendo, muitas vezes, do que exatamente se tratam e os desafios de cada uma delas.

\subsection{Caracterização do Público Participante da Pesquisa}

Dos 14 estudantes solicitados a responderem o questionário, 13 deles o fizeram. Observase, no Gráfico 1, que a maioria dos participantes pertence ao curso de Engenharia de Computação, da Universidade Estadual de Feira de Santana (pública), correspondendo a $69 \%$ dos respondentes, contrários aos $31 \%$ da Universidade Salvador (privada).

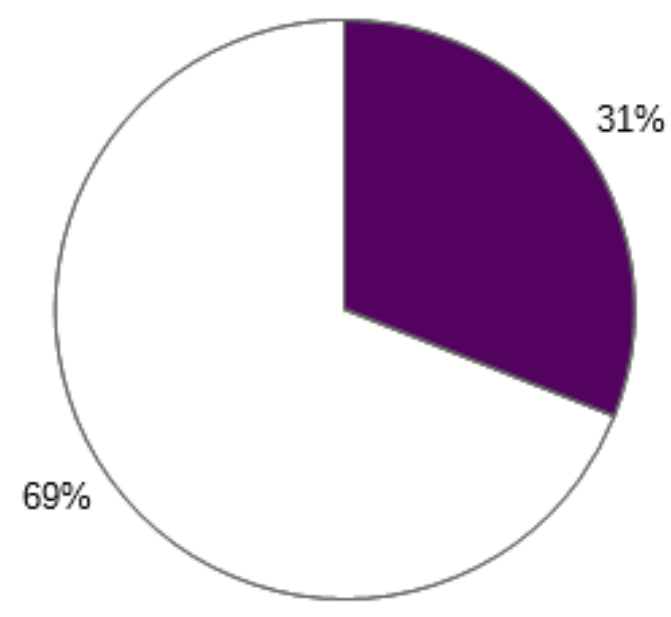

Universidade Estadual de Feira de Santana

Universidade

Salvador

Gráfico 1. Universidade a que pertencem os estudantes.

Observa-se, no Gráfico 1, que mais da metade são estudantes da Universidade Estadual de Feira de Santana e poucos da Universidade Salvador.

Algumas das possíveis razões para esse fato são: (1) maior disponibilidade dos estudantes do ensino superior público para atividades de pesquisa e extensão, visto que, no geral, dedicam mais tempo dentro da Universidade e envolvidos com outras atividades, além do 
ensino em sala de aula; (2) no geral, os estudantes do ensino superior privado, da área de Computação, trabalham durante o dia e estudam à noite, enquanto os do ensino público estudam durante o dia. Isso, muitas vezes, impossibilita dedicação de 20 horas para as atividades de pesquisa e/ou extensão; (3) maior incentivo e valorização da instituição pública para atividades de pesquisa e extensão, ainda que isto venha crescendo também no ensino privado; (4) maior incentivo à participação docente e discente em eventos científicos, em instituições públicas e (5) afastamento e/ou desentendimento dos estudantes do ensino privado do universo da pesquisa/extensão.

Esse perfil e discussão serão retomados na Seção de resultados e discussão. Além da Universidade, os estudantes foram questionados sobre o tipo e o período de vínculo de cada um deles. O Gráfico 2 apresenta o quantitativo em relação ao tipo de vínculo. Como três dos estudantes tiveram dois tipos de vínculo, durante esse período, ora bolsista, ora voluntário, o número total de respondentes para este questionamento foi de 16, do qual 8 deles como bolsista de iniciação científica (IC); 1, bolsista de extensão; 5, voluntários de IC e 2, voluntários de extensão.

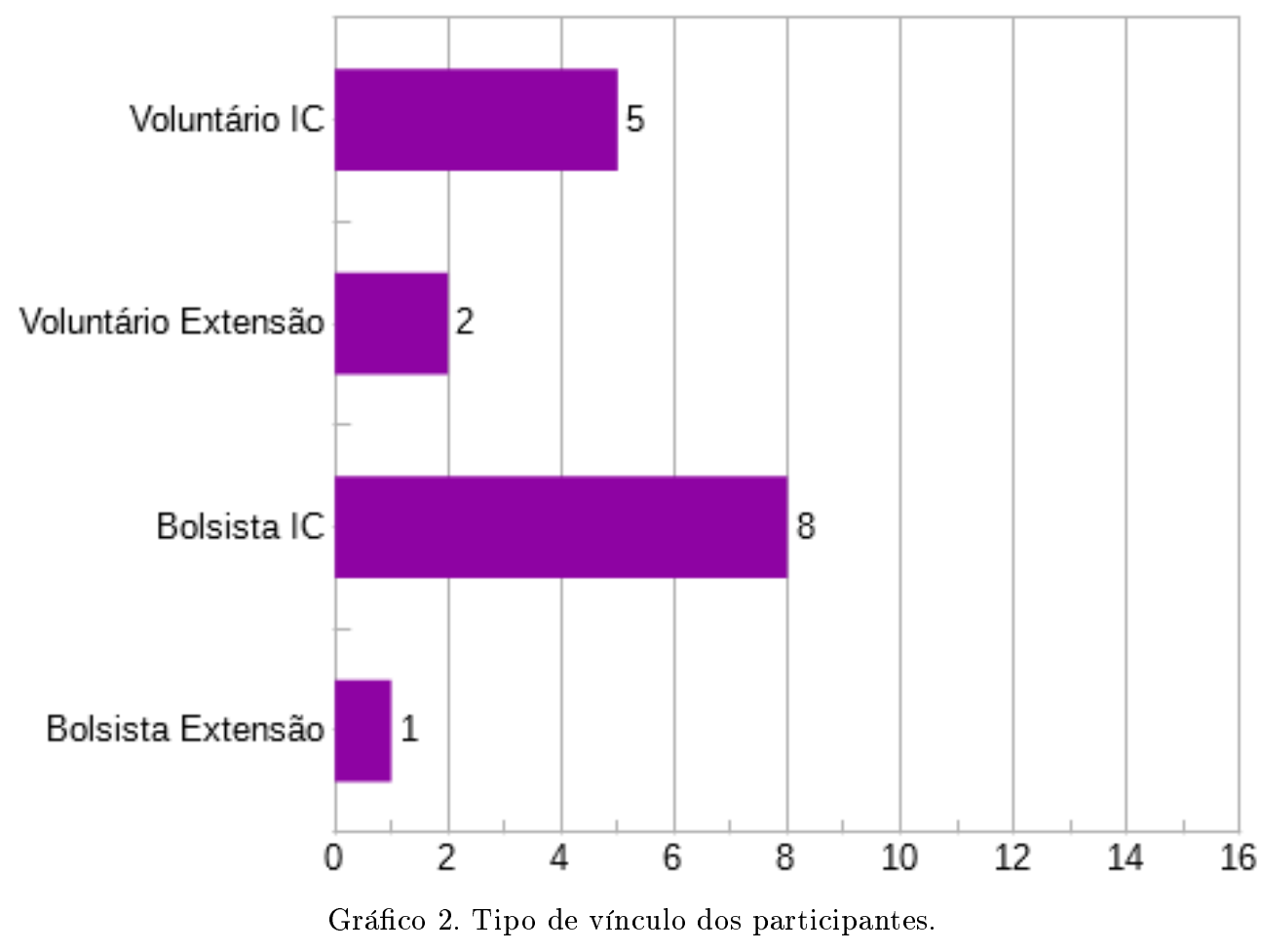

Os dois estudantes que, no momento, se encontram como voluntários, tinham submetido planos de trabalho para o novo período, de agosto/2016 a julho/2017, na tentativa de renovação de bolsa, mas não obtiveram êxito. Isso é um dos motivos de desestímulo dos estudantes de IC, que começam um trabalho e desejam continuá-lo em um segundo momento, mas veem seus planos e sonhos interrompidos. É bem frustrante para o professor e, em especial, para os estudantes. $\mathrm{O}$ professor tem interesse em ver um bom trabalho continuado, dando novos frutos e sem interrupção, e o estudante, por dois motivos principais, um deles a vontade também em continuar colaborando com o projeto de pesquisa e com a atividade que esta- 
va desempenhando, e o segundo, a necessidade muitas vezes do valor da bolsa que recebe mensalmente.

Um motivo comum ao professor e ao estudante é que, normalmente, o primeiro ano de bolsa é aquele em que o estudante está se familiarizando com o projeto, com os objetivos almejados, com o referencial teórico e com as tecnologias necessários para a produção de soluções. Dessa forma, é o segundo ano de bolsa o momento mais frutífero, no qual, após esse estágio inicial, é possível a concretização de soluções mais substanciais. O Gráfico 3 apresenta a quantidade de meses do vínculo de cada um dos estudantes, na categoria bolsista de IC, além da indicação da permanência do vínculo. Os três primeiros estudantes são aqueles que ainda se mantém como bolsista IC (Sim), enquanto os cinco últimos são aqueles que já tiveram sua bolsa encerrada (Não).

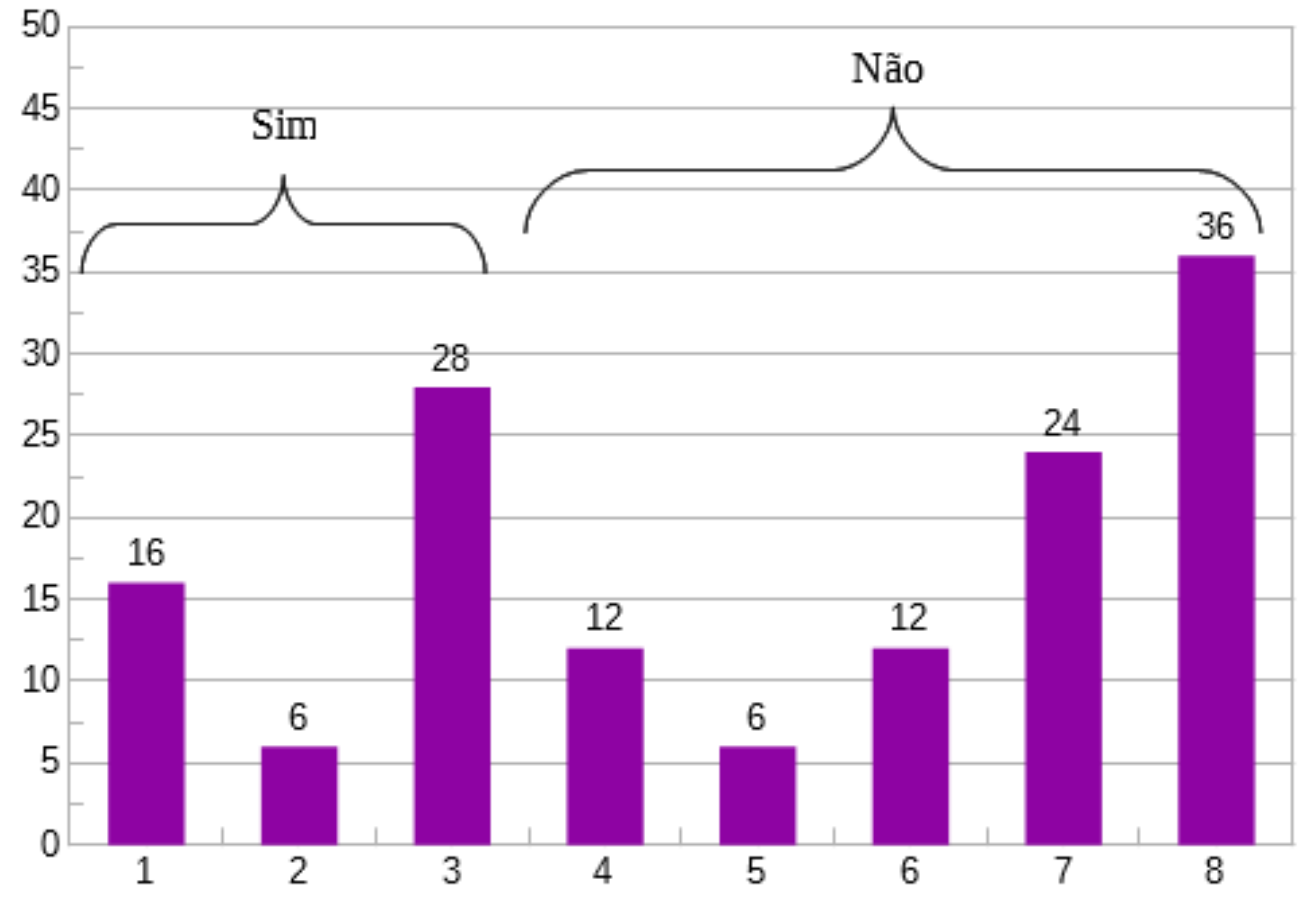

Gráfico 3. Tempo e atualidade dos vínculos dos bolsistas IC.

Percebe-se que o tempo médio de permanência como bolsista IC é cerca de 18 meses (um ano e meio). Além disso, há uma exceção de apenas 6 meses, dentre aqueles que já finalizaram a bolsa, que foi o caso de um estudante que submeteu um plano de trabalho aprovado, mas concedido apenas 6 meses após o início das demais bolsas, em substituição a um bolsista desistente de outro projeto. Em relação aos bolsistas de extensão, temos apenas um estudante vinculado a um projeto de extensão, com um vínculo atual (ainda não encerrado) de 7 meses.

O Gráfico 4 apresenta o tempo e a permanência dos estudantes como voluntários IC nos projetos.

Dos 5 estudantes voluntários IC, o segundo e o terceiro, que possuem, cada um deles, 12 meses vinculados ao projeto, são os únicos que ainda estão atuantes nesta categoria. Os demais já se desvincularam dos projetos. Vale ressaltar que esses 12 meses como voluntários não são contínuos, sendo 6 meses anteriores ao vínculo como bolsista 2015-2016, e os outros 
6 meses a partir do término desse vínculo. O quinto estudante, com 36 meses de vínculo como voluntário, se comparado aos demais, é o mais fora da curva. Ele era colega de turma na Universidade do estudante bolsista IC com mesma quantidade de tempo vinculado ao mesmo projeto (estudante 8 do Gráfico 3), o que pode justificar sua permanência.

Em relação ao voluntariado de extensão, 2 estudantes colaboram com o bolsista de extensão no seu trabalho desde o seu início, portanto, por 7 meses.

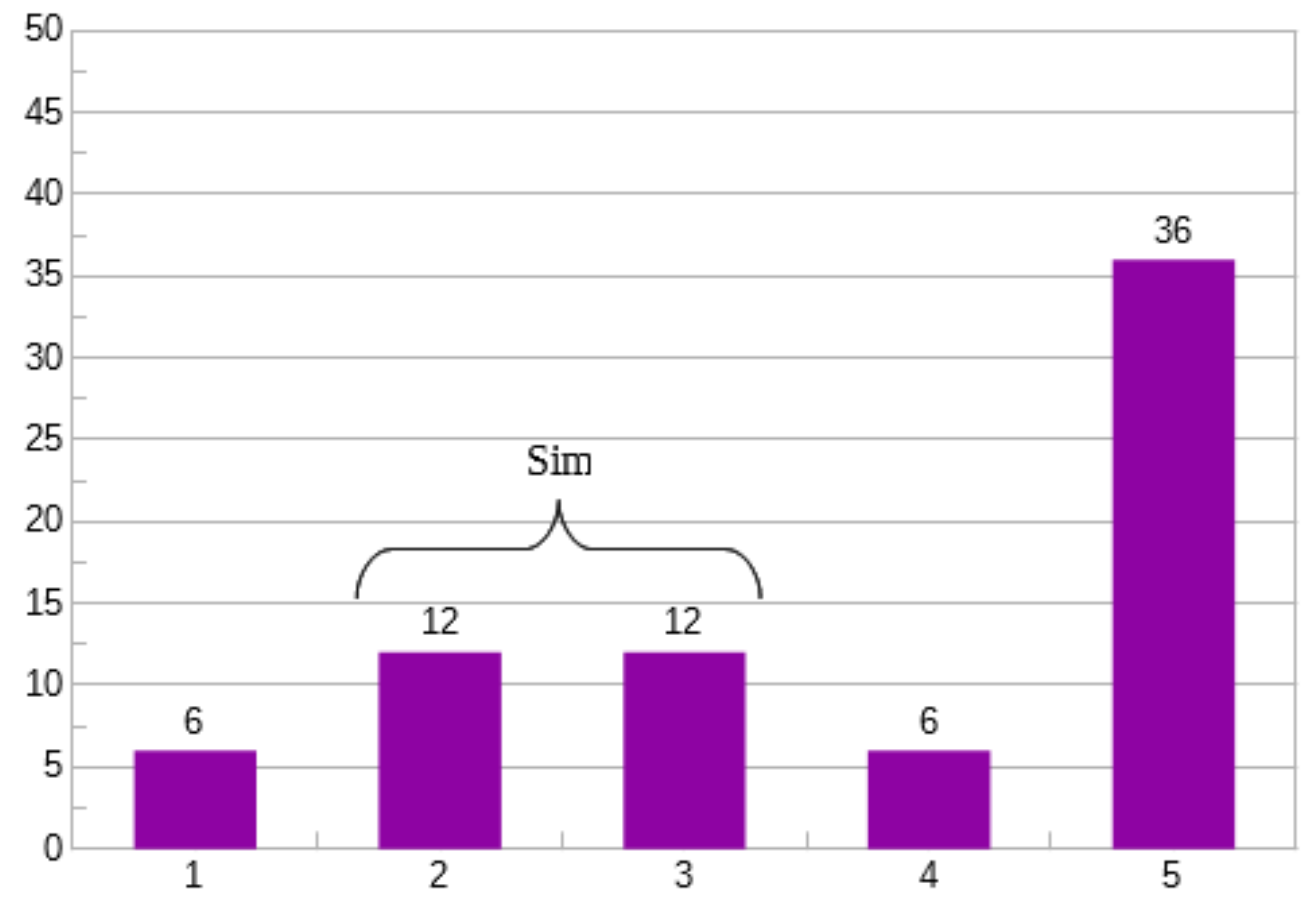

Gráfico 4. Tempo e atualidade dos vínculos dos voluntários IC.

\subsection{Breve Relato da Experiência de Orientação}

Esta seção apresenta um breve relato dos projetos e atividades desenvolvidas neste período, na tentativa de contextualizar o cenário do processo de orientação, além das impressões e percepções na perspectiva do orientador.

Um dos projetos de pesquisa, aquele da Universidade Salvador, está voltado para a representação e difusão de conhecimentos para as pessoas com deficiência visual. Deste projeto, participaram e/ou ainda participam 4 estudantes, com atividades voltadas para o desenvolvimento de soluções tecnológicas para esse público. Os dois primeiros participantes (um bolsista e um voluntário), que ficaram por mais tempo no projeto, por 3 anos consecutivos, apresentaram soluções web e mobile que permitem às pessoas com deficiência visual representarem conhecimentos a partir de mapas conceituais textuais/vocais ${ }^{14-16}$. Além dessas duas soluções, uma terceira web foi desenvolvida para a representação de informações geradas (ideias, fatos e metas) a partir de sessões PBL (Problem Based Learning), também para pessoas com deficiência visual (ainda sem publicação) e uma quarta, para a representação de diagramas de entidade relacionamento (banco de dados), também para o mesmo público $^{9}$. 
O segundo projeto de pesquisa, coordenado por outro colega docente, se ampliou de uma pesquisa voltada para o estudo de PBL em cursos de graduação e pós-graduação e as tecnologias relacionadas a essa estratégia educacional, para soluções educacionais dedicadas a todos os públicos, inclusive às pessoas com deficiência visual, com algumas publicações vinculadas $^{17-18}$. Dentre as propostas de trabalho vinculadas a esse projeto, orientados neste período, estão o desenvolvimento de três objetos de aprendizagem com interfaces visual e vocal, dois deles para a área de matemática por meio do BEM (do inglês: Blinds, Education and Mathematics) e BEM Expressões ${ }^{11,13}$, e o terceiro um jogo da velha multidisciplinar, intitulado BBE (do inglês: Blinds and Basic Education) ${ }^{10}$. Além desses três trabalhos, um quarto estudante bolsista IC se dedicou a avaliação das interfaces do jogo BEM, construção de instrumentos de avaliação, casos de testes, e estudo de gamification, para inclusão das orientações e critérios da gamificação no jogo BEM ${ }^{12}$.

Em todas essas orientações, conseguimos, além da produção de ferramentas voltadas para a educação, para pessoas com e sem deficiência visual, publicações em eventos científicos da área e revistas. Neste percurso, percebe-se que algumas habilidades não trabalhadas de forma mais sistêmica e intensa no ensino, são permitidas e necessárias no trabalho de pesquisa, tais como a habilidade da escrita e a habilidade oral. A todo tempo, o estudante está sendo solicitado a ler e escrever sobre o que vem investigando, desde a construção do seu plano de trabalho, até a produção de relatórios exigidos pelos órgãos de fomento e instituições, e artigos científicos que divulguem seus trabalhos. Acompanhando a escrita, vem a apresentação de boa parte destes escritos em eventos científicos, dentro e fora da instituição de origem.

Essas habilidades são inicialmente mais difíceis para os estudantes, mas, com o tempo, e com a devida condução do orientador, vão sendo melhoradas e incentivadas. Neste percurso, foi muito interessante perceber o crescimento destas habilidades. Alguns dos estudantes começaram a participar da pesquisa no segundo e terceiro semestres dos cursos e desconheciam, inclusive, o que se esperava de um pesquisador; o que deveriam estudar, investigar e como escrever dentro das normas exigidas, ficando "perdidos" em meio ao novo e ao desconhecido. A própria idade e a imaturidade acadêmica dos estudantes são elementos que devem ser considerados e que interferem neste início de caminhada de um pesquisador iniciante. Por isso, o orientador deve ser uma pessoa com capacidade e sensibilidade suficientes para conduzi-los com firmeza, mas não com arrogância ou petulância. Ser humilde é uma característica que deve acompanhar o pesquisador, seja ele aquele que se inicia nessa jornada (um estudante, por exemplo) ou alguém que já tem uma caminhada um pouco maior (um professor/orientador, por exemplo).

Este impacto inicial, ainda que difícil, é importante para o estudante perceber que a autonomia e a iniciativa são outras competências necessárias a um pesquisador e que o papel do orientador não é de "carregá-lo no colo", mas sim de apontar caminhos, soluções e tecnologias. Não cabe ao orientador executar o plano de trabalho proposto pelo estudante, implementar as ferramentas propostas, escrever seus relatórios ou coisas semelhantes. Seu papel, durante todo o percurso, é de estar próximo ao orientando (seja presencial ou virtualmente), propondo caminhos, tecnologias; indicando possíveis publicações; dando força nos momentos difíceis, de desânimo e/ou desencanto; ouvi-los, atentamente, seja nas demandas acadêmicas ou pessoais (às vezes, necessário); cobrar compromisso às atividades e flexibilizar, quando possível. Neste período, houve acontecimentos em todos os sentidos, desde atividades que não foram cumpridas por descaso (o décimo quarto estudante solicitado a responder esta pesquisa e que não o fez), ou outras que não aconteceram por problemas pessoais ou dificuldades em se apropriar das tecnologias necessárias.

É importante também enfatizar que, muitas vezes, seu orientando conhece muito mais 
de uma tecnologia ou solução do que o próprio orientador, em especial quando se trata da área de Computação, que é muito dinâmica. Isso não é demérito algum para o orientador, e uma oportunidade enorme do professor aprender com o estudante, em um processo contínuo de ida e volta, afinal, aprende-se o tempo todo, para todo resto da vida.

O projeto de extensão é um projeto da área de saúde, mais especificamente, da área de Enfermagem, voltado para o estudo e implantação da Sistematização do Atendimento de Enfermagem (SAE) em um hospital público da cidade de Feira de Santana. Para apoiar a SAE, o bolsista e os voluntários de extensão estão empenhados no desenvolvimento de um aplicativo mobile para este fim e, para tanto, já vêm interlocutando com enfermeiras(os) do projeto, tanto no espaço universitário quanto no espaço hospitalar.

Também no projeto de extensão, há a necessidade inicial de aproximação teórica com o contexto envolvido, e, de forma semelhante, as habilidades de leitura, escrita, oralidade, e competências como autonomia, escuta atenta, iniciativa, proatividade são essenciais. No caso da extensão, amplia-se o contato com a comunidade, neste caso, com as(os) enfermeiras(os) de um hospital público da cidade.

Nestes projetos citados acima (pesquisa e extensão), foi possível a aproximação destes estudantes com a Sociedade, estreitando relações, e entregando os resultados produzidos para além dos "muros" da Universidade, beneficiando, por exemplo, pessoas com deficiência visual, crianças em processo de formação e enfermeiros no exercício profissional. A perspectiva da responsabilidade social encanta esses estudantes, e foi um dos motivos de aproximação destes com o orientador e com os projetos de pesquisa e extensão mencionados.

\section{Apresentação e Discussão dos Resultados}

Nesta seção, serão apresentados os resultados dos outros questionamentos feitos aos participantes dessa trajetória, expressos através de falas, trechos de respostas abertas, depoimentos e números associados, com o objetivo, não de propor soluções para o processo de orientação de pesquisadores e extensionistas, mas de apontar alguns caminhos e, sobretudo, refletir sobre a importância da pesquisa e extensão para estes estudantes e do papel docente neste percurso.

Inicialmente, foram questionados em relação à compreensão da diferença entre a pesquisa e a extensão. Embora duas das treze respostas tenham sido "não sei" e uma delas em branco, as outras dez foram muito semelhantes, mostrando-nos que compreendem bem essa diferença. No geral, apontaram que a pesquisa propõe a construção e o desenvolvimento de conhecimentos pelo estudante, e a extensão, a aproximação do estudante com a comunidade e a sociedade, buscando ajudá-las de alguma forma.

Quando questionados sobre se consideravam que o estudante deveria começar a construir uma carreira de pesquisa já na Graduação, todos eles foram unânimes em afirmar que sim. Talvez essa resposta positiva esteja associada ao fato de que todos eles já participam deste universo, e possui alguma maturidade acadêmica e entendimento do processo. É possível que se outros estudantes, não conhecedores de perto da pesquisa e da extensão, fossem submetidos à mesma pergunta, o resultado pudesse ter sido diferente.

Ainda associada a esta pergunta, foi pedido a eles que justificassem a resposta anterior. Foi comum nas respostas dos estudantes a ideia da oportunidade de buscar e agregar novos conhecimentos; aprimorar, amadurecer e solidificar outros apreendidos dentro e fora de sala de aula e ampliar esses conhecimentos. Em aproximadamente $70 \%$ das respostas, apareceram as palavras "conhecer" e "conhecimento". Além disso, associaram também à possibilidade de conhecerem outras áreas de conhecimento, permitindo-os maior aproximação com a área de TI e melhor escolha da carreira e áreas possíveis a serem seguidas profissionalmente. 
ISSN: 2358-1271. Int. J. of Alive Eng. Educ. (IJAEEdu). (Online). Goiânia, v. 4, n. 1, p. 83-102, jan./june 2017.

Palavras como "carreira", "área", "crescimento profissional", "ramo de atuação", "área de TI" apareceram em, aproximadamente, $38 \%$ das respostas.

Além desses percentuais maiores, outras justificativas relevantes foram apontadas. São elas:

“(...) pesquisa científica (...) desenvolve a autonomia para o aprendizado e o desenvolvimento de projetos. Estas competências são valorizadas em todas as áreas" (Participante $3)$.

"Por questões de prática e a presença de uma orientação para guiar o aluno no caminho certo" (Participante 5).

"(...) ambiente propício para o aprendizado" (Participante 7).

"(...) trabalhar em equipe" (Participante 8).

"Iniciar a carreira de pesquisa ainda na graduação contribui para o amadurecimento acadêmico do estudante" (Participante 9).

"Importante para o desenvolvimento de conteúdos que não são ensinados durante as aulas convencionais (...)" (Participante 12).

Observa-se, nas respostas acima, a percepção dos estudantes em relação à importância da orientação, do trabalho em equipe e do desenvolvimento da autonomia para o aprendizado de conteúdos, não necessariamente vistos em sala de aula. Ampliando a questão anterior, foram questionados sobre se a pesquisa teria a função de formar apenas cientistas. Apenas um deles respondeu que "sim", e os demais, "não", por entenderem que a pesquisa vai além disso. Alguns relatos podem ser resumidos pelas falas a seguir:

"A pesquisa auxilia, além da construção de conhecimento, a formação do homem. Através da iniciação, é possível também amadurecer o indivíduo envolvido e fazer com que este também possa se preparar melhor para o meio acadêmico e profissional" (Participante $2)$.

"As competências desenvolvidas na pesquisa científica são valorizadas em todas as áreas" (Participante 3).

"Como dito anteriormente, a pesquisa também contribui para formação para o mercado de trabalho" (Participante 4).

"A pesquisa, além de formar cientistas, forma cidadãos, pois o processo de aquisição de conhecimento torna o aluno mais crítico e ciente das suas possibilidades enquanto indivíduo para com a Sociedade" (Participante 7).

"Tem como função também lidar com pessoas" (Participante 8).

"A pesquisa tem a função de formar pessoas. Contribui tanto pra o crescimento pessoal, cultural e profissional" (Participante 9).

"Pesquisa está relacionada a desenvolver pró-atividade e resolução de problemas" (Participante 10).

Boa parte citou que, além do papel de aproximar o estudante da ciência, a pesquisa forma, sobretudo, cidadãos, pessoas mais críticas e capazes de ajudar a sociedade. Imbuídos dessas possibilidades, foram questionados sobre os impactos/benefícios da pesquisa e da extensão para o graduando, em uma questão na qual os itens já eram apresentados a eles, conforme o Gráfico 5. Também foram perguntados sobre as possíveis desvantagens encontradas no percurso da pesquisa e da extensão, em uma questão aberta, com os resultados apresentados a seguir. 
O Gráfico 5 apresenta, portanto, os itens: (1) Aquisição de novos conhecimentos, (2) Aprendizado da dinâmica do trabalho em grupo, (3) Compreensão e entendimento do universo da pesquisa, (4) Entendimento do papel do orientador, (5) Necessidade de estudo auto dirigido, (6) Ampliação da habilidade de leitura, (7) Ampliação da habilidade de escrita, (8) Aproximação com a área acadêmica e da docência, (9) Maior senso crítico da profissão, (10) Maior senso crítico social, (11) Aproximação com outros pares (colegas) de semestres diferentes, (12) Publicações acadêmico-científicas e (13) outros.

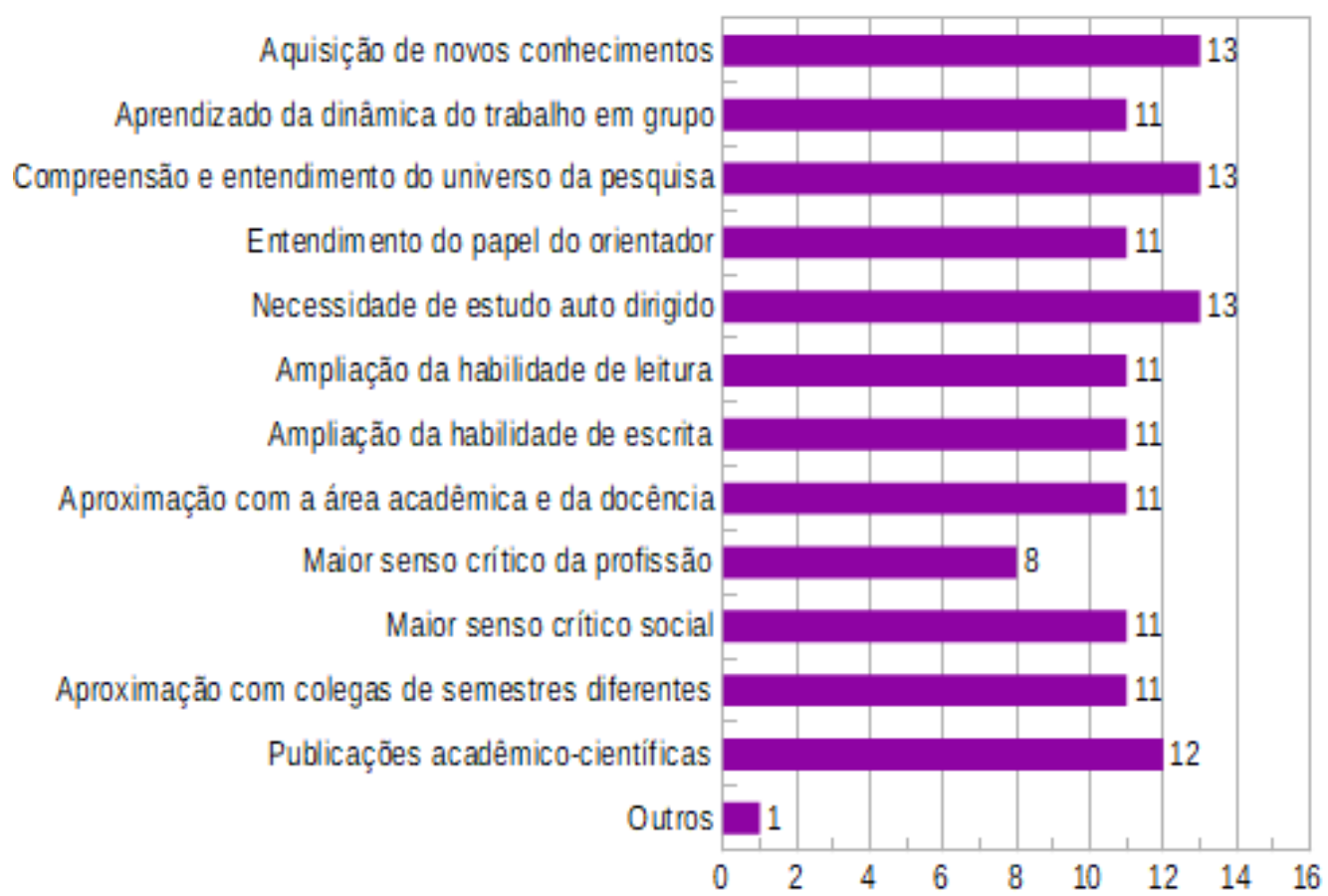

Gráfico 5. Impactos/benefícios da pesquisa e da extensão para o graduando.

Observa-se que, como foram 13 respondentes, todos eles (100\%) concordaram em 3 dos 13 itens acima: aquisição de novos conhecimentos, compreensão e entendimento do universo da pesquisa e necessidade de estudo autodirigido. A importância de publicações acadêmicocientíficas foi apontada como relevante por $12(92.3 \%)$ dos 13 estudantes, e maior senso crítico profissional por 8 deles $(61.5 \%)$. Os demais itens foram relevantes para $11(84.6 \%)$ dos 13 participantes. Foram também questionados sobre o grau de importância de cada um dos itens marcados. Desta questão, destaca-se que o menor impacto da pesquisa e da extensão (em grau de relevância) dentre todos é a ampliação da habilidade de leitura. Para eles, estar imerso nesse universo não aumenta essa habilidade, possivelmente porque já seja algo mais inerente ao dia a dia de sala de aula e à necessidade de estudar e ler regularmente.

Em relação às desvantagens, no geral relataram a dificuldade em se dividirem entre os estudos e demandas de sala de aula e à dedicação de 20 horas semanais para o trabalho de pesquisa e/ou extensão. Outros dois fatos importantes e que despertam atenção é o valor da bolsa pago pelos órgãos de fomento ou instituições de ensino, considerado muito baixo às demandas discentes, e o fato da pouca divulgação e incentivo das próprias instituições para os eventos internos de pesquisa e extensão e, sobretudo, os externos. Para um deles, a pouca 
ISSN: 2358-1271. Int. J. of Alive Eng. Educ. (IJAEEdu). (Online). Goiânia, v. 4, n. 1, p. 83-102, jan./june 2017.

visibilidade dos resultados desses trabalhos vem também desta baixa divulgação e incentivo, e completa, exemplificando, que, nos eventos internos promovidos especialmente para a pesquisa e para a extensão, somente participam os professores avaliadores, os professores orientadores (e nem sempre) e os estudantes que estão apresentando seus trabalhos.

Diante destes questionamentos, foi desejado saber que palavra representaria o percurso de cada estudante, seja na pesquisa ou na extensão. "Superação" apareceu em 4 respostas, "Aprendizado" em 2 delas, seguidas de: "Sucesso", "Entusiasmo", "Conquista", "Dedicação", "Descobrimento", "Oportunidade" e "Diferencial". Todas essas palavras representam bem esse momento de envolvimento do estudante com esse novo universo, seja ele o da pesquisa ou o da extensão. Estão todos eles imbuídos em aprender e superar limites, sejam estes pessoais (introspecção, dificuldade de trabalhar em grupo, de ouvir, etc.), ou profissionais/técnicos (desconhecimento de linguagens ou técnicas de programação, dificuldade de expressar textualmente o que pensa, etc.), conquistar novos conhecimentos e espaços acadêmicos e/ou profissionais, garimpar e descobrir novas oportunidades, e, para que tudo isso tenha sucesso e se torne um diferencial, é preciso ter dedicação e entusiasmo.

Nesta trajetória, o orientador tem papel fundamental, podendo funcionar com um estímulo ou desestímulo para o discente, a depender da forma como conduz o processo e como interage com o orientando. Precisamos, a todo tempo, cuidar do que se exige do estudante e da forma como essa exigência é posta. É possível falar a mesma coisa de diversas formas, elevando a responsabilidade do estudante e, em paralelo, sua competência, ou minimizando todo seu esforço e potencial. Por isso, é importante exigir do estudante que cumpra prazos, atividades planejadas e a execução do plano de trabalho, mas também é necessário, em alguns momentos, flexibilizar e entender que, nessa trajetória, existem ainda as exigências do ensino (aulas, avaliações, trabalhos e outros) e as demandas pessoais (família, entretenimento e outros). Um estudante saudável emocionalmente e psicologicamente é um pesquisador muito mais produtivo.

Em função do entendimento de que o orientador tem papel fundamental no processo de orientação de um trabalho de pesquisa e extensão, foram perguntados sobre que motivos os levaram a escolha do orientador e como é o seu relacionamento pessoal e acadêmico com o professor/orientador. Os Gráficos 6, 7 e 8 trazem, respectivamente, essas respostas.

Em relação aos motivos para a escolha do orientador, apresentados no Gráfico 6, os estudantes podiam selecionar mais de um item. Dos respondentes, apenas dois deles selecionaram uma única opção: o Participante 1, por afinidade, e o Participante 5, pelo projeto/linha de pesquisa. Sete dos 13 participantes responderam que a escolha se deu em função da afinidade e da indicação de outras pessoas; 10 deles, pela competência acadêmica do orientador; 9 , incluindo o Participante 5 citado, pelo projeto/linha de pesquisa.

Em relação ao relacionamento com o orientador, tanto pessoal (Gráfico 7) quanto acadêmico (orientação) (Gráfico 8), foi utilizada uma escala linear de 1 a 5, sendo 1 'Péssimo', 2 - 'Ruim', 3 - 'Razoável', 4 - 'Bom' e 5 - 'Ótimo'.

É bom constatar que tanto o relacionamento pessoal quanto o acadêmico, da maioria dos estudantes, foram classificados como "ótimo" (10 e 11 estudantes, respectivamente). No Gráfico 7, três estudantes classificaram o relacionamento pessoal com o orientador como "péssimo", "razoável" e "bom", e, por coincidência, foram os dois estudantes voluntários de extensão, que possuem menos tempo de vínculo com o projeto e com o orientador, o que pode justificar essa resposta; e um estudante que não devolveu os resultados do seu trabalho como esperado e, por esse motivo, foi chamado atenção pelo orientador. É claro que essas justificativas são na perspectiva do orientador e não do orientando. Vale a pena, no próximo trabalho de avaliação, questioná-los o porquê dessa resposta, inclusive para entendimento do que é necessário melhorar, tanto por parte do professor quanto pelo estudante. 


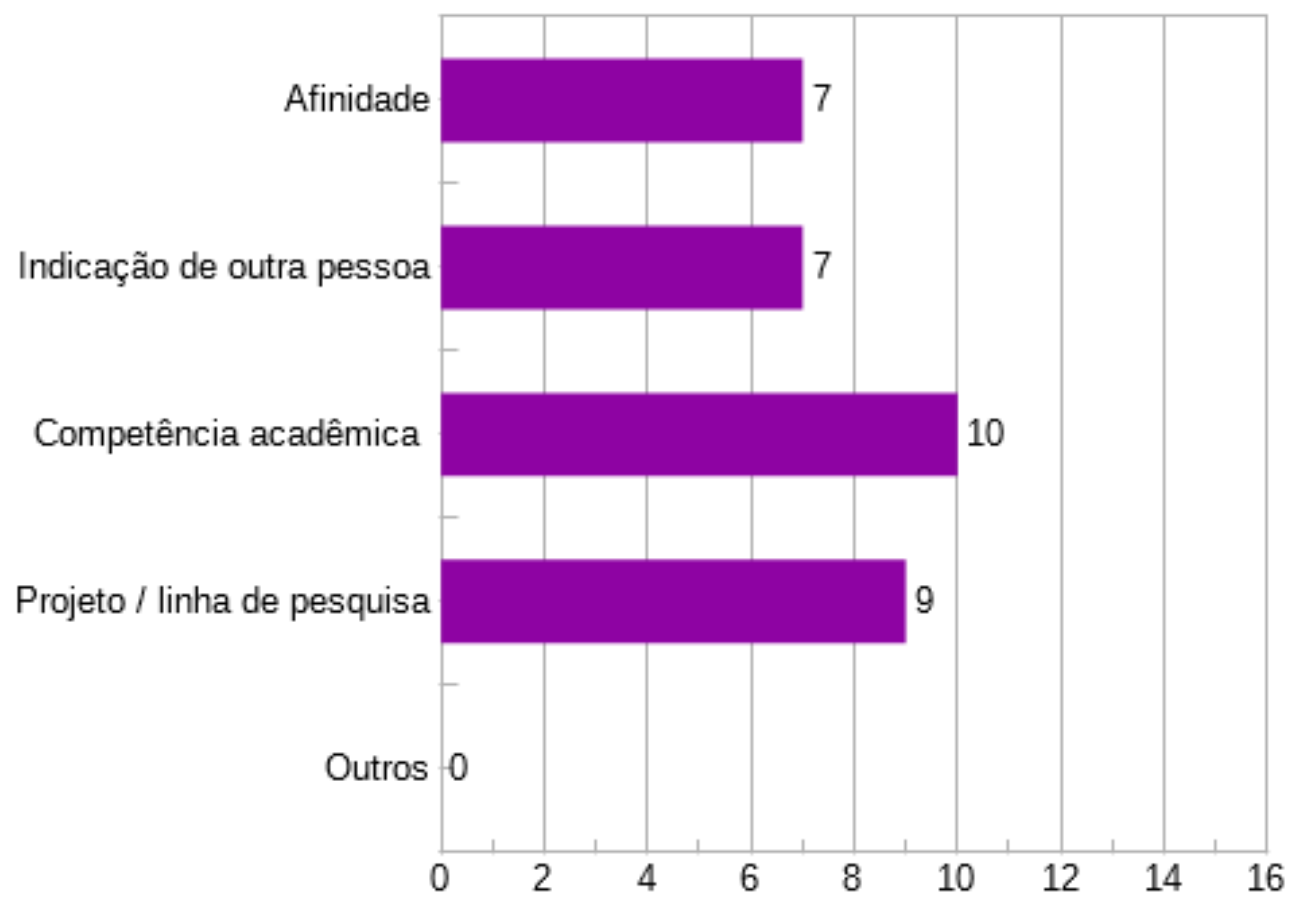

Gráfico 6. Motivos para escolha de seu orientador.

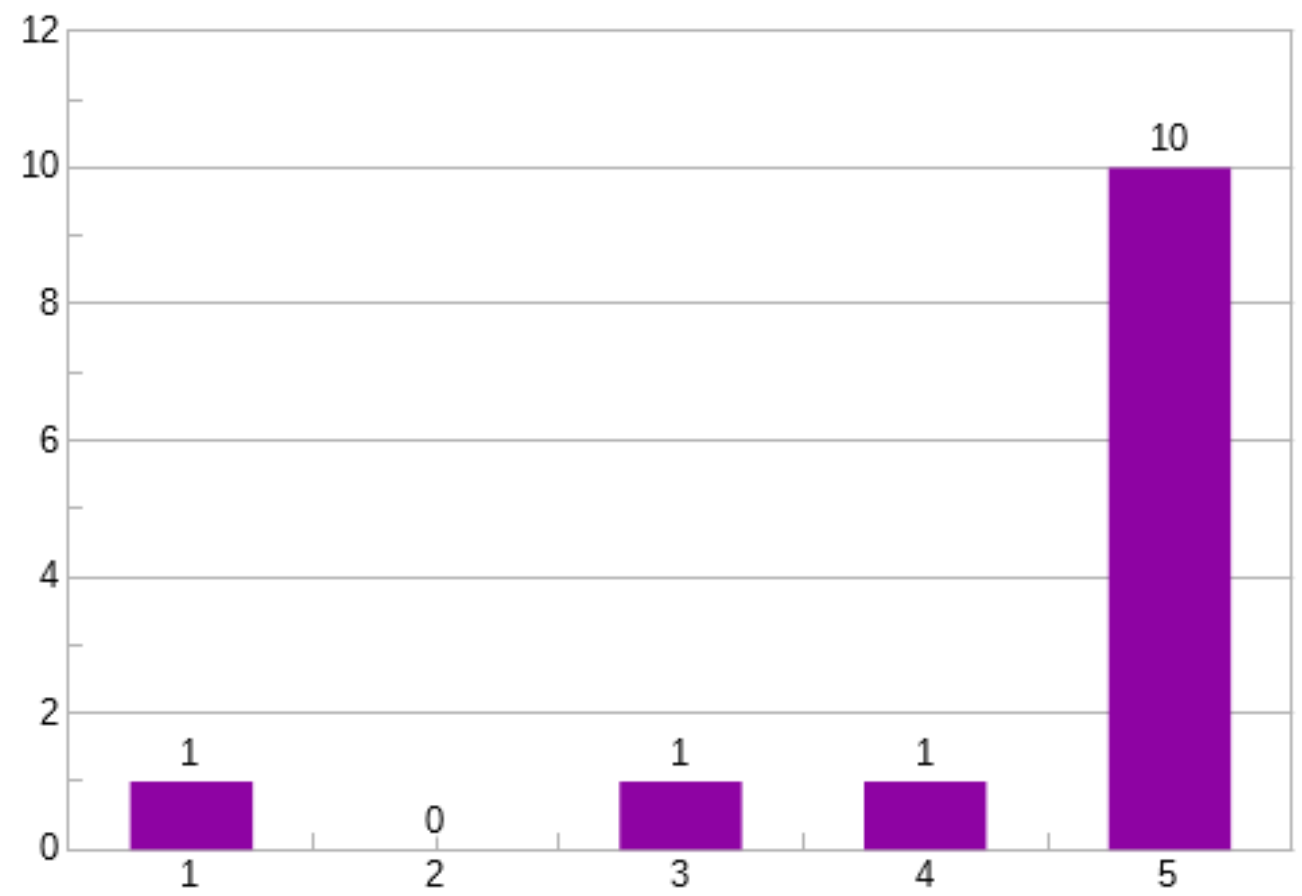

Gráfico 7. Classificação do relacionamento pessoal com o orientador. 
De forma semelhante, os mesmos dois estudantes voluntários de extensão foram aqueles que avaliaram como "ruim" e "razoável" o relacionamento acadêmico (orientação) com o orientador, apresentado no Gráfico 8. De alguma forma, essa avaliação preliminar já ajudará a iniciar um diálogo com estes estudantes, para entender os motivos e o que é possível já delinear como metas para melhorar qualitativamente esses relacionamentos.

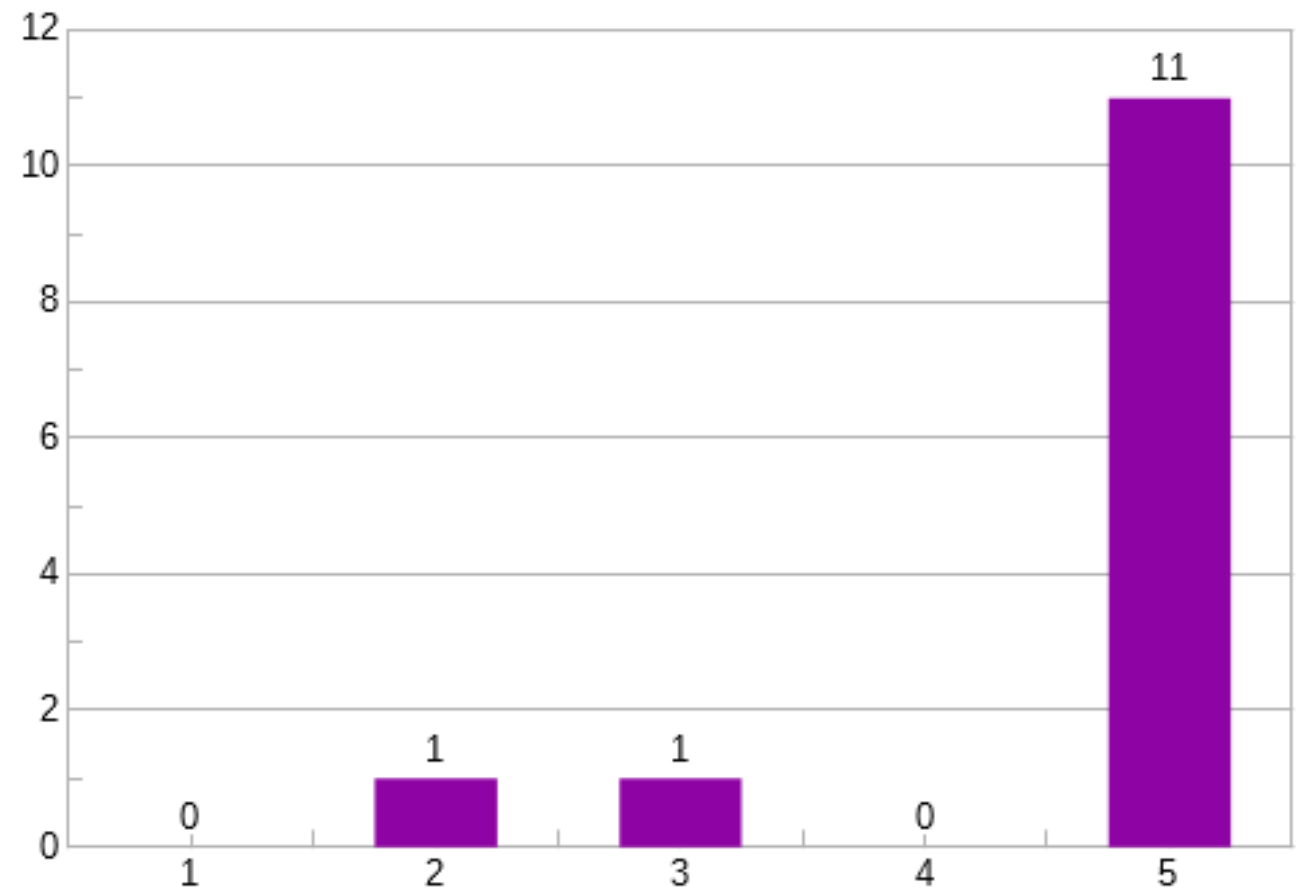

Gráfico 8. Classificação do relacionamento acadêmico (orientação) com o orientador.

\section{Conclusões}

O presente trabalho apresentou um relato de experiência de orientação de discentes da área de Computação, classificados em bolsistas e voluntários, tanto na pesquisa quanto na extensão, de duas Universidades do estado da Bahia, uma pública e outra privada, mais especificamente da cidade de Feira de Santana. Durante esse período de orientação e de atividades científicas e extensionistas, estudantes e professor/orientador puderam experimentar as vantagens e desvantagens dessas atividades, os desafios e os impactos inerentes ao processo e as possibilidades acadêmicas, técnicas, sociais e comunitárias.

A intenção foi, principalmente, de relatar essa experiência nas perspectivas docente e discente, na tentativa de reflexão sobre a prática docente e sobre a importância dessas atividades para os estudantes. Proporcionar ao estudante "sair do espaço de sala de aula", adquirir outros e novos conhecimentos, investir na criatividade, na autonomia são alguns dos resultados positivos dessas atividades. Além disso, é claro, a possibilidade do seu estudo ser remunerado e de conviver, mais de perto, como seu professor/orientador e com outros pares (colegas), de semestres iguais ou diferentes. Essa trajetória proporciona, ao estudante, amadurecimento técnico-científico, inter e intra pessoal, e de se sentir útil socialmente, quando percebem seus resultados, suas produções (softwares, dentre outros) disponibilizados para a comunidade. 
Os desafios para os estudantes que se envolvem com a pesquisa e/ou extensão é, sem dúvida, administrar bem o tempo entre o ensino, suas demandas, e as atividades e exigências da pesquisa/extensão, além de se manterem motivados, a todo tempo, com esse trabalho, frente aos desafios. Essa motivação pode ser intrínseca ao sujeito que se mostra mais investigativo e criativo, ou pode ser promovida e estimulada pelo professor/orientador. O orientador, portanto, é essencial neste processo e precisa estar atento aos indícios de desestímulo. Como esse artigo aborda a percepção de, apenas, um professor/orientador, um trabalho futuro importante seria o levantamento da percepção de outros docentes, das mesmas instituições, envolvidos em pesquisa e extensão.

De qualquer sorte, esses resultados preliminares são relevantes, pois demonstram a prática docente e a preocupação em relação ao papel do orientador nesta trajetória. Segundo Silva, é de extrema importância quando "o próprio professor se propõe a investigar a sua prática, o seu 'fazer pedagógico', divulgar a sua pesquisa com uma intenção prática de reverter os resultados para o acervo da prática da sala de aula e para o aperfeiçoamento profissional. Trata-se de uma abordagem a partir e na própria prática"19.

Para o professor/orientador, os desafios estão em lapidar estes estudantes, que chegam imaturos academicamente, com deficiências na leitura, na escrita científica e formal, e na oralidade, ou com a falta de entendimento do verdadeiro papel do estudante/pesquisador, que deve buscar, investigar, com autonomia, sem esperar do professor respostas e soluções prontas. Esse comportamento se justifica, muitas vezes, pelos vícios do ensino tradicional, no qual o estudante assume um papel mais passivo e o professor, mais ativo, o que precisa ser invertido e repensado a todo tempo por ambos.

Em contrapartida, sem dúvida, a orientação é uma atividade prazerosa e muito enriquecedora. Aprende-se com os estudantes, com a comunidade para a qual são apresentadas as soluções/ferramentas computacionais e com aqueles com os quais nos relacionamos a todo momento, tais como outros professores, instituições parceiras, setores institucionais e órgãos de fomento. Aprende-se tecnicamente (novas técnicas e métodos, novos frameworks, novas linguagens de programação, etc.) e habilidades interpessoais, como ser educado, saber ouvi-los atentamente, compartilhar soluções, ser solidário e parceiro com o colega, e, nos trabalhos citados neste artigo, também como saber lidar com pessoas com deficiência visual e com enfermeiros(as).

Para Silva, "a prática cotidiana do professor é um desafio permanente que resiste a fórmulas, modelos, soluções externas, e um convite para um ensino criativo, experimental e para uma pesquisa na ação". A Universidade, como espaço de ensino aprendizagem, deve se fazer sentir para "além de seus muros", irradiando seus conhecimentos e suas práticas para a Sociedade $^{19}$.

\section{Agradecimentos}

Os agradecimentos para as instituições de ensino Universidade Estadual de Feira de Santana e Universidade Salvador (Campus Feira), aos órgãos de fomento FAPESB e CNPQ, pela concessão de bolsas aos estudantes (quando bolsistas), e para os estudantes bolsistas ou voluntários de pesquisa e extensão, participantes deste levantamento inicial.

\section{Referências}

1. ANDRADE, F. C. B.; MOITA, F. M. G. S. Ensino-pesquisa-extensão: um exercício de indissociabilidade na pós-graduação, textitRevista Brasileira de Educação, vol.14, n.41, Rio de Janeiro, p. 269, 2009. 
2. ARROYO, D. M. P.; ROCHA, M. S. P. M. L. Meta-avaliação de uma extensão universitária: estudo de caso, Revista da Avaliação da Educação Superior,v. 15 n. 2, Sorocaba, p. 131-157, 2010.

3. CORRÊA, E. J. Extensão universitária, política institucional e inclusão social, Revista Brasileira de Extensão Universitária, v. 1, n. 1, ChapecÓ p.12-15, 2003.

4. ALMEIDA, A. S. A contribuição da extensão universitária para o desenvolvimento de Tecnologias Sociais, 2010. Informativo Eletrônico da Rede de Tecnologia Social, p. 96, Brasília, 2010.

5. MARTINS, L. M. Ensino-pesquisa-extensão como fundamento metodológico da construção do conhecimento na universidade, São Paulo: Unesp, 2012.

6. SERRANO, R. M. S. M. Conceitos de extensão universitária: um diálogo com Paulo FreireConceitos . Grupo de Pesquisa em Extensão Popular. Disponível em: $<$ http://www.prac.ufpb.br/copac/extelar/atividades/discussao/artigos/conceitos_de_extensao_universitaria.pdf $>$. Acesso em: 02 dezembro 2016.

7. PLANO NACIONAL DE EXTENSÃO UNIVERSITÁRIA PNExt - Institui o Plano Nacional de Extensão Universitária PNExt. Disponível em: < http://pdi.ufabc.edu.br/wpcontent/uploads/2011/09/Plano-Nacional-de-Extens \%C3 \%A3o-Universi \%C3 \%A1ria-20112020.pdf > Acesso em: 02 dezembro 2016.

8. MACEDO, R. S. Outras luzes: um rigor intercrítico para uma etnopesquisa política. In: Um rigor outro sobre a questão da qualidade na pesquisa qualitativa: educação e ciências humanas, Salvador: EDUFBA, 2009, p. 75-126.

9. GUEDES, R. A.; PAIXÃO, R. S. S.; SENA, C. P. P. Ferramenta de Apoio ao Processo de Ensino Aprendizagem para Pessoas com Deficiência Visual na Construção do Diagrama Entidade Relacionamento, In: ESCOLA REGIONAL DE COMPUTAÇÃO BAHIA, ALAGOAS E SERGIPE, 16.,2016, Maceió. anais... p. 5-14, 2016.

10. SANTANA, K. C.; SENA, C. P. P.; SANTOS, A. J. O. S.; FERNANDES, A. L. B.; MACEDO, R. S. Blinds, Basic Education: um jogo multidisciplinar para a educação básica de crianças com deficiência visual e videntes, In: ESCOLA REGIONAL DE COMPUTAÇÃO BAHIA, ALAGOAS E SERGIPE, 16., 2016, Maceió. anais... p. 15-24, 2016.

11. SANTANA, K. C.; SENA, C. P. P.; SANTOS, A. J. O. S.; FERNANDES, A. L. B.; MACEDO, R. S. Blinds, Education and Mathematics: jogo eletrônico de tabuleiro como estratégia educativa para o ensino-aprendizagem das quatro operações básicas da matemática, In: ESCOLA REGIONAL DE COMPUTAÇÃO BAHIA, ALAGOAS E SERGIPE, 16., 2016, Maceió. anais... p. 47-55, 2016.

12. SANTANA, K. C.; SENA, C. P. P.; SANTOS, A. J. O. S.; FERNANDES, A. L. B.; MACEDO, R. S. Análise do uso do Objeto de Aprendizagem BEM no processo educacional de pessoas com deficiência visual e videntes, In: ESCOLA REGIONAL DE COMPUTAÇÃO BAHIA, ALAGOAS E SERGIPE, 16., 2016, Maceió. anais... p. 191-200, 2016.

13. SENA, C. P. P.; SANTOS, A. J. O. S.; FERnANDES, A. L. B.; MACEDO, R. S.; PINTO, G. R. P. R. A utilização de jogos na educação matemática para crianças com deficiência visual e videntes, In: ESCOLA REGIONAL DE COMPUTAÇÃO BAHIA, ALAGOAS E SERGIPE, 15., 2015, Salvador. Anais..., 2015.

14. SILVA, D. F.; SENA, C. P. P. Sistema de representação do conhecimento para pessoas com deficiência visual (SRC-DV) e suas possibilidades educacionais", In: CONGRESSO INTERNACIONAL DEL CONOCIMIENTO, 4., 2015, Santiago. Anais..., 2015.

15. SILVA, D. F.; SENA, C. P. P.; OLIVEIRA W. S. SRC-DV: Sistema De Representação Do Conhecimento Para Pessoas Com Deficiência Visual, In: INTERNATIONAL CONFERENCE ON CONCEPT MAPPING, 6., 2014, São Paulo. textitanais..., 2014.

16. SENA, C. P. P.; Silva, D. F.; CARVAlhO, R. S.; CASAS, T. H. P.; PEREIRA, H. B. B. Sistema de representação de conhecimento para pessoas com deficiência visual: etapas iniciais, In: ESCOLA REGIONAL DE COMPUTAÇÃO BAHIA, ALAGOAS E SERGIPE, 13., 2013, São Cristóvão. Anais..., 2013.

17. SIlVA, A. P.; SENA, C. P. P.; FILHO, S. S. S.; SANTOS, P. E.; PINTO, G. R. P. R. Adap- 
ISSN: 2358-1271. Int. J. of Alive Eng. Educ. (IJAEEdu). (Online). Goiânia, v. 4, n. 1, p. 83-102, jan./june 2017. 101

tabilidade da interface do aplicativo web PBL-VS para uso por pessoas com deficiência visual, In: ESCOLA REGIONAL DE COMPUTAÇÃO BAHIA, ALAGOAS E SERGIPE, 13., 2013, Aracaju. Anais..., 2013. .

18. PINTO, G.; DANTAS, A. L.; SENA, C. P.; Carvalho, R, Integração de saberes na formação do engenheiro: potencialização da responsabilidade social a partir da aplicação dos conhecimentos de engenharia na educação. In: CONGRESSO BRASILEIRO DE EDUCAÇÃO EM ENGENHARIA, 16., 2013, Gramado. Anais..., 2013.

19. SILVA, T. M. N. A construção do currículo na sala de aula: o professor como pesquisador. São Paulo: EPU, 1990, p. 74. 
